\title{
Correction to: Risk stratification with vasodilator stress SPECT myocardial perfusion imaging in patients with elevated cardiac biomarkers
}

\author{
Shreyas Gowdar, MD, ${ }^{\mathrm{a}}$ Alan W. Ahlberg, MA, ${ }^{\mathrm{a}}$ Mridula Rai, MD, ${ }^{\mathrm{a}}$ \\ William H. Perucki, MD, ${ }^{a}$ Kevin D. Felpel, MD, ${ }^{b}$ John A. Savino III, MD, ${ }^{c}$ \\ Eric L. Alter, $M D,{ }^{c}$ Milena J. Henzlova, $M D,{ }^{c}$ and W. Lane Duvall, $M^{a}$ \\ a Hartford Hospital Division of Cardiology, Hartford Healthcare Heart and Vascular Institute, \\ Hartford, CT \\ b Department of Medicine, University of Connecticut School of Medicine, Farmington \\ c Mount Sinai Division of Cardiology, Mount Sinai Heart, Mount Sinai Medical Center, New York, \\ NY
}

doi: $10.1007 / \mathrm{s} 12350-019-01688-x$

\section{CORRECTION TO: J NUCL CARDIOL HTTPS://DOI.ORG/10.1007/S12350-019-01661-8}

The following error (highlighted in bold below) appears in the Results section of the Abstract:

A total of 503 patients were followed for an average of $33.6 \pm 16.2$ months, with a mean age of 69.3 years; $53.7 \%$ male; and a majority (88.7\%) of them undergoing vasodilator stress. A significant increase in all-cause mortality was seen based on the severity of TPD results for all vasodilators $(P<.0001)$ and regadenoson $(P<.0001)$. Similar prognostic ability was seen for cardiac mortality. This association was maintained even after adjustment for cardiac risk factors, previous coronary disease, and troponin quartiles. MPI results (stress TPD and LVEF) added to traditional cardiac risk factors, and troponin values resulted in a significant incremental increase in the ability to predict all-cause and cardiac mortality, and stress TPD remained independently predictive for both all-cause and cardiac mortality in a multivariate model.

Publisher's Note Springer Nature remains neutral with regard to jurisdictional claims in published maps and institutional affiliations.
The original article can be found online at https://doi.org/10.1007/ s12350-019-01661-8.

Reprint requests: W. Lane Duvall, MD, Hartford Hospital Division of Cardiology, Hartford Healthcare Heart and Vascular Institute, 80 Seymour Street, Hartford, CT 06102; lane.duvall@hhchealth.org J Nucl Cardiol 2020;27:1381.

$1071-3581 / \$ 34.00$

Copyright (C) 2019 American Society of Nuclear Cardiology. 